\title{
CONTRIBUIÇÃO PARA O MELHOR APROVEITAMENTO DE FLUÍDO DE PERFURAÇÃO DE POÇOS DE PETRÓLEO - UMA ABORDAGEM UTILIZANDO PROCESSAMENTO DE IMAGEM
}

\author{
E. N. MATTA ${ }^{1}$, W. O. ASSIS ${ }^{1 *}$, M. M. GOMES ${ }^{1}$, V. P. BARBOSA ${ }^{2}$, R. GEDRAITE ${ }^{2}$, \\ C.H. ATAÍDE ${ }^{2}$ \\ ${ }^{1}$ Centro Universitário do Instituto Mauá de Tecnologia, Campus de São Caetano do Sul \\ ${ }^{2}$ Universidade Federal de Uberlândia, Faculdade de Engenharia Química \\ *e-mail: wanderson.assis@maua.br
}

\begin{abstract}
RESUMO
A recuperação do fluido de perfuração é importante na operação de poços de petróleo sob a ótica ambiental e econômica. A remoção dos fragmentos e detritos gerados durante a perfuração é essencial para permitir o reaproveitamento do fluido, garantir uma melhor eficiência na sua utilização durante o processo de perfuração bem como evitar o descarte do produto, o qual contém produtos químicos nocivos para o meio ambiente. Os equipamentos utilizados para a separação sólido-líquido incluem três grupos sequenciais: peneiras vibratórias, bateria de hidrociclones e centrífuga decantadora. Um dos maiores desafios é caracterizar o tamanho das partículas e material sólido nas correntes de entrada e saída das peneiras utilizadas no processo de separação, contribuindo para a melhoria operacional e aumento da vida útil das telas utilizadas e com isso para a melhor qualidade do sistema de tratamento do fluido de perfuração. Nesse sentido, este trabalho apresenta uma abordagem utilizando algoritmo de processamento de imagem visando a caracterização da granulometria do material sólido presente no fluido de perfuração de poços de petróleo.
\end{abstract}

\section{INTRODUÇÃO}

As características da manifestação do petróleo na natureza fazem da exploração e produção do petróleo uma atividade de grande complexidade tecnológica (ALMEIDA, 2002). A exploração do petróleo é uma atividade essencialmente arriscada e de custo elevado (COELHO et al., 2005).

A Figura 1 apresenta o esquema de uma sonda de perfuração sendo composta essencialmente por uma torre de sondagem, a qual serve como grua para baixar e içar as tubulações de aço e contém na ponta a broca de perfuração, além de uma casa de máquina que abriga os motores responsáveis pelo acionamento da grua, da broca e da bomba do fluido de perfuração.

O trabalho de perfuração exige injeção de uma mistura de argila, água e produtos químicos, por meio de uma bomba de fluido, na tubulação de perfuração. A função do fluido de perfuração é remover os detritos da rocha perfurada, lubrificar e arrefecer a broca, estabilizar a parede do poço, além de evitar a erupção de gás, óleo ou água (ALMEIDA, 2002). Esse fluido é injetado por bombas para o interior da coluna de perfuração através da cabeça de injeção e retorna à superfície pelo espaço anular formados pelas paredes do poço e pela coluna. 
Figura 1 - Esquema típico de uma sonda de perfuração

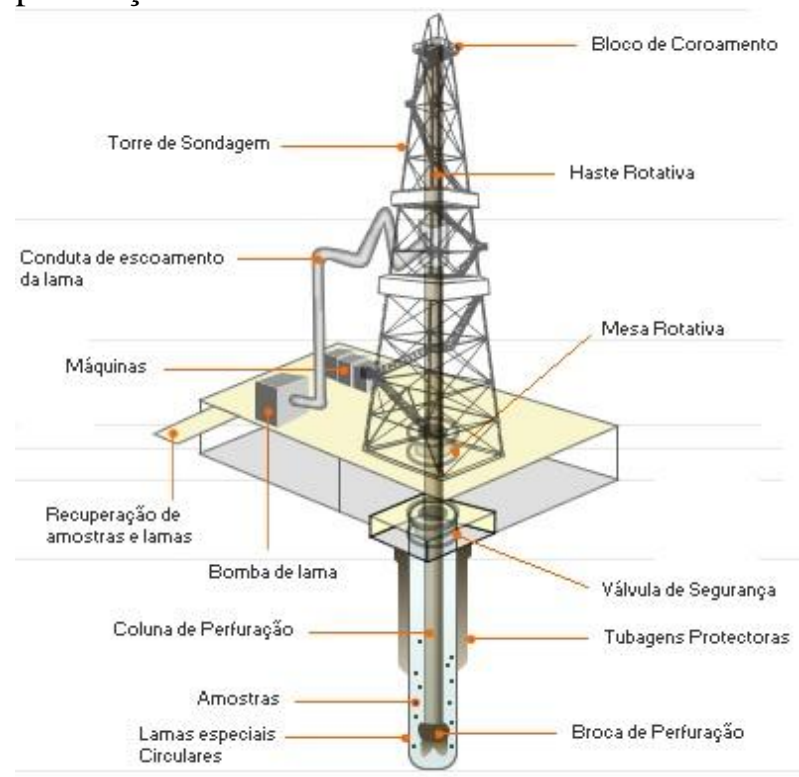

Fonte: Adaptado de Galp (2011).

O tratamento do fluido de perfuração é de suma importância na operação de perfuração de poços de petróleo, sob o ponto de vista operacional, ambiental e econômico. Este fluido possui sólidos em suspensão que têm origem na ação de corte das formações rochosas pela broca de perfuração ou em sua formulação inicial. O diâmetro dos sólidos de perfuração varia dependendo do tipo de rocha, tamanho e formato da broca de perfuração. A partir desses detritos retornados à superfície é possível estimar a distância do ponto atual da broca até a jazida de petróleo por meio da análise do tamanho desses detritos em conjunto com o conhecimento do tipo e composição do solo sendo escavado. Assim, a análise contínua dos sólidos permite detectar os primeiros indícios de hidrocarbonetos nas formações rochosas.

Trabalhos recentes abordam estudos sobre os equipamentos utilizados para a separação sólido-líquido do fluído de perfuração (LOBATO et al., 2011) (GUERREIRO, 2013).

\subsection{Separação de Sólidos na Perfuração de Poços}

O principal objetivo das atuais técnicas de separação de sólidos é a redução de custo, removendo de forma eficiente os sólidos e minimizando a perda de fluido contido nos mesmos (PEREIRA, 2013). Como os sólidos possuem uma larga faixa de distribuição granulométrica, devem-se utilizar vários tipos de equipamentos.

Os equipamentos utilizados para a separação sólido-líquido incluem três grupos sequenciais: peneiras vibratórias, bateria de hidrociclones e centrífuga decantadora. As peneiras têm um papel fundamental na eficiência global no processo de separação de sólidos, pois são os primeiros equipamentos a partir do flowline (PEREIRA, 2013).

Segundo a Sociedade Americana de Engenharia Mecânica (ASME, 2004), para avaliar a capacidade de remoção dos equipamentos é necessário considerar a origem dos sólidos e classifica-los pelas dimensões conforme Tabela 1.

Como exemplo de detritos extraídos durante o processo de perfuração pode-se citar a imagem apresentada na Figura 4.

A eficiência na remoção de sólidos pode ser computada de duas maneiras: quanto maior a fração de sólidos removidos, maior a eficiência; quanto maior a fração de sólidos no efluente de descarte, melhor é a eficiência de remoção. Ambos os aspectos devem ser considerados (GUERREIRO, 2013). Um dos principais desafios nesse processo é caracterizar o tamanho das partículas e material sólido nas correntes de entrada e de saída da peneira. Assim, é possível ajustar condições operacionais, tais como: a vazão do fluido, a frequência e amplitude de vibração da esteira, além da inclinação da tela de filtração visando melhorar a eficiência do processo de retirada dos detritos e minimizar o seu desgaste. 
Tabela 1 - Classificação de sólidos quanto ao tamanho (comprimento máximo).

\begin{tabular}{|c|c|c|}
\hline Denominação & $\begin{array}{c}\text { Faixa de } \\
\text { Tamanho } \\
\quad(\mu \mathrm{m})\end{array}$ & $\begin{array}{l}\text { Tipos de } \\
\text { Partículas }\end{array}$ \\
\hline Cascalho & $\begin{array}{c}\text { Maior que } \\
2000\end{array}$ & $\begin{array}{c}\text { Sólidos de } \\
\text { perfuração, } \\
\text { cascalhos, } \\
\text { pedras. }\end{array}$ \\
\hline Areia & 74 a 2000 & $\begin{array}{c}\text { Areia, } \\
\text { sólidos de } \\
\text { perfuração. }\end{array}$ \\
\hline Lama & 2 a 74 & $\begin{array}{l}\text { Barita, } \\
\text { silte, } \\
\text { sólidos de } \\
\text { perfuração } \\
\text { finos. }\end{array}$ \\
\hline Colóides & Menor que 2 & $\begin{array}{c}\text { Bentonita, } \\
\text { argila, } \\
\text { sólidos de } \\
\text { perfuração } \\
\text { ultrafinos. }\end{array}$ \\
\hline
\end{tabular}

Fonte: Adaptado de ASME (2004).

Por fim, além de remover fatores humanos do processo, a automação pode contribuir para melhorar a vida útil da esteira utilizada na separação e transporte destes detritos. Caso existam detritos muito grandes para determinado tipo de esteira o desgaste também será comparativamente maior que em uma esteira bem dimensionada.

Também não podemos esquecer os aspectos ambientais, visto que os sólidos que retornam do poço devem ser descartados. Para tanto, devem ser lavados e secos de forma eficiente a fim de eliminar qualquer resíduo do fluido de perfuração.

\section{PROCESSAMENTO DE IMAGENS}

A aplicação de técnicas de processamento de imagens no desenvolvimento de sistemas de visão computacional (GONZALEZ e WOODS, 2000), é uma área de pesquisa fascinante que tem produzido recentemente resultados de grande relevância para inúmeros segmentos da sociedade. Podemos citar, por exemplo, aplicações de identificação e segmentação de objetos ou imagens humanas, reconstrução 3D de cenas reais, aplicações de prototipagem rápida ( $\mathrm{RP}$ - Rapid Prototyping) para produção de objetos com formas complexas a partir de dados tridimensionais, rastreamento em tempo real e navegação de robôs móveis ou veículos não tripulados, controle de processos de manufatura ou sistemas industriais (DENIS, 2009), dentre outros.

Algumas das principais técnicas utilizadas em aplicações de processamento de imagem digital onde o objetivo é a classificação a partir das dimensões do objeto incluem a binarização e a conectividade. A binarização da imagem consiste na transformação da imagem para níveis branco e preto puro. Para isso obtém-se um histograma onde são analisados os valores na escala greyscale obtidos para cada pixel da imagem e sua distribuição em termos de intensidade. Uma maneira de determinar os níveis da imagem binarizada (preto ou branco) é comparar os valores dos pixels da matriz greyscale utilizando um limiar (threshold). Quando um único limiar é utilizado para uma imagem inteira, o processo é conhecido como limiarização global. Quando o limiar muda ao longo da imagem, temos a limiarização variável. Se o limiar é variável e definido a partir das propriedades de uma vizinhança (por exemplo, a média dos pixels da vizinhança), temos a limiarização local (GONZALES e WOODS, 2000). Uma das técnicas de limiarização de imagens é o algoritmo conhecido como filtro de Sobel. 
Trata-se de uma operação usada em processamento de imagens especialmente em algoritmos aplicados na detecção de contorno (KIMMEL et al., 2005).

Muitas vezes ao se capturar imagens digitais em um ambiente real que apresenta diferentes tonalidades e fontes de luz diretas ou refletidas podem ocorrer imperfeições e interferências indesejadas, o que poderia prejudicar o processamento da imagem em questão. Com o objetivo de remover pontos destoantes de luz ou refinar bordas podem ser utilizados algoritmos digitais que permitem implementar diversos tipos de filtros. $\mathrm{O}$ funcionamento básico de um filtro morfológico consiste em analisar cada pixel da imagem alterando seu valor segundo um critério predeterminado. Para realizar tal tarefa define-se um elemento estruturante com um ponto de ancoragem em seu centro. Embora o método possa produzir alguma deterioração nas regiões de borda ainda assim, na maioria dos casos, a utilização de filtros permite melhorar bastante a qualidade do algoritmo de classificação de objetos por processamento de imagens.

Neste trabalho propõe-se o desenvolvimento de um aplicativo para realizar o processamento e análise de imagens visando caracterizar as partículas presentes no fluido de perfuração mas utilizando algoritmo bastante distinto dos apresentados em (GUILHERME et al., 2011) e (SERAPIÃO et al., 2013).

O aplicativo foi desenvolvido utilizando o software LabVIEW ${ }^{\mathrm{TM}}$ o qual permite realizar o processamento de imagens previamente gravadas ou capturadas em tempo real por uma câmera posicionada sobre peneira vibratória com o objetivo de localizar e identificar as partículas presentes no fluido de perfuração, caracterizando-as com base em suas dimensões.

\subsection{Materiais e Métodos}

Para realizar o projeto foram utilizadas imagens capturadas de um equipamento real numa aplicação de tratamento de fluído de perfuração mas armazenadas em computador. Contudo o aplicativo desenvolvido permite introduzir, com relativa facilidade, câmeras para capturar as imagens em tempo real. Testes foram realizados utilizando câmera WebCam convencionais mas também a câmera digital IP (Internet Protocol) Feasso $^{\mathrm{TM}}$ modelo f-ipcam03 comprovam a versatilidade do aplicativo desenvolvido.

A Figura 2 apresenta a interface gráfica desenvolvida utilizando o aplicativo NI Vision o qual é integrado ao software LabVIEW ${ }^{\mathrm{TM}}$. $\mathrm{O}$ aplicativo desenvolvido pode ser resumido pelo diagrama de blocos da Figura 3. A interface gráfica inclui diversas funcionalidades, a saber: seleção da fonte das imagens a serem utilizadas (externas, capturadas por câmera, ou obtidas por meio de figuras armazenadas); calibração da imagem utilizando um padrão, podendo opcionalmente realizar a manipulação de contraste, brilho e gama da imagem; processamento incluindo conversão de imagens para tons de cinza, binarização e seleção de filtros; eliminação de conglomerados de rochas acumulados nas bordas e interferências; determinação do número de partículas e cálculo da área de cada uma delas, bem como da área média; opção de utilização de sistema de monitoramento remoto utilizando página da $W e b$. 
Figura 2 - Interface gráfica do aplicativo em LabVIEW ${ }^{\mathrm{TM}}$

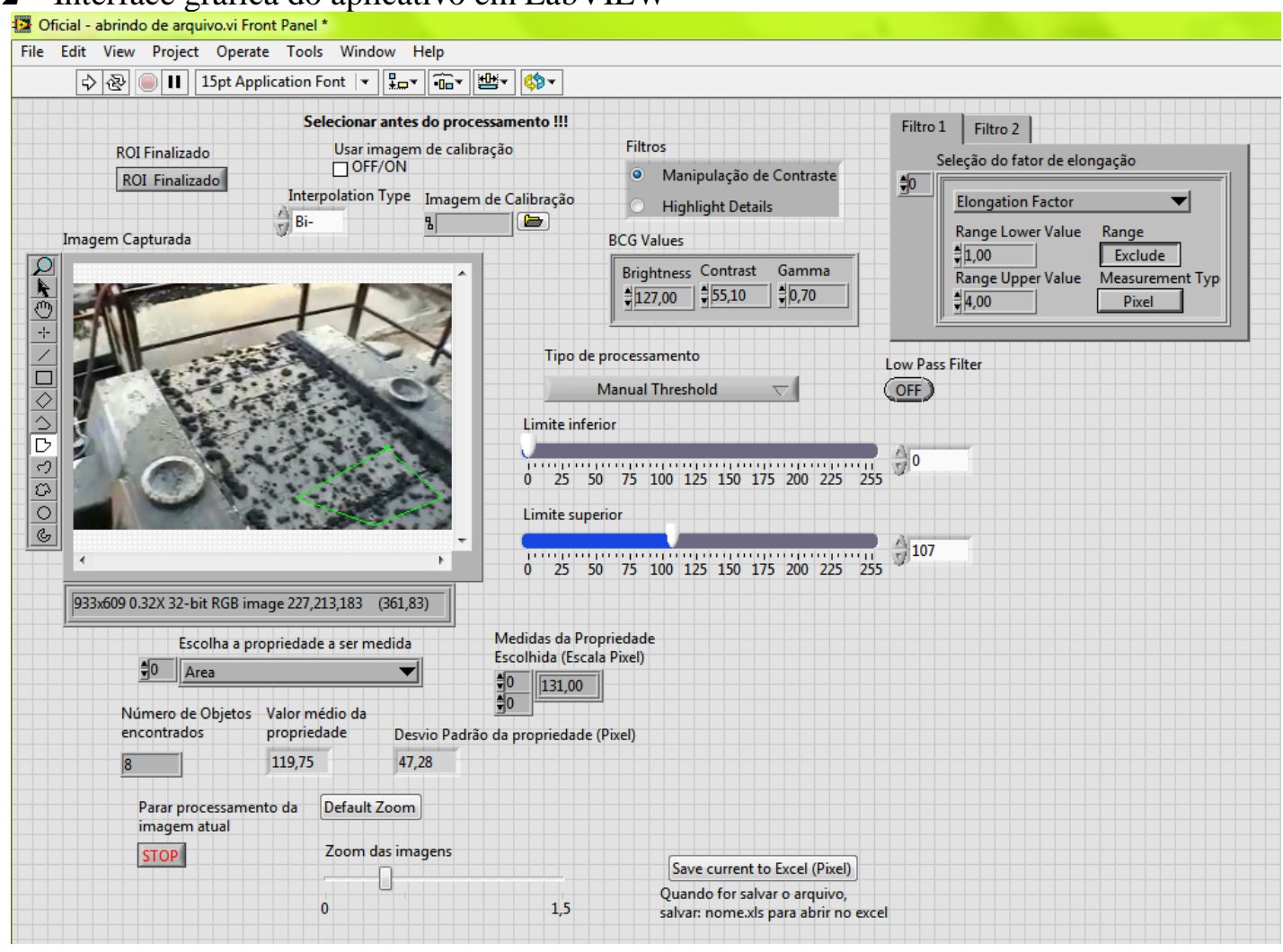

Figura 3 - Fluxograma do algoritmo de processamento de imagem em LabVIEW ${ }^{\mathrm{TM}}$
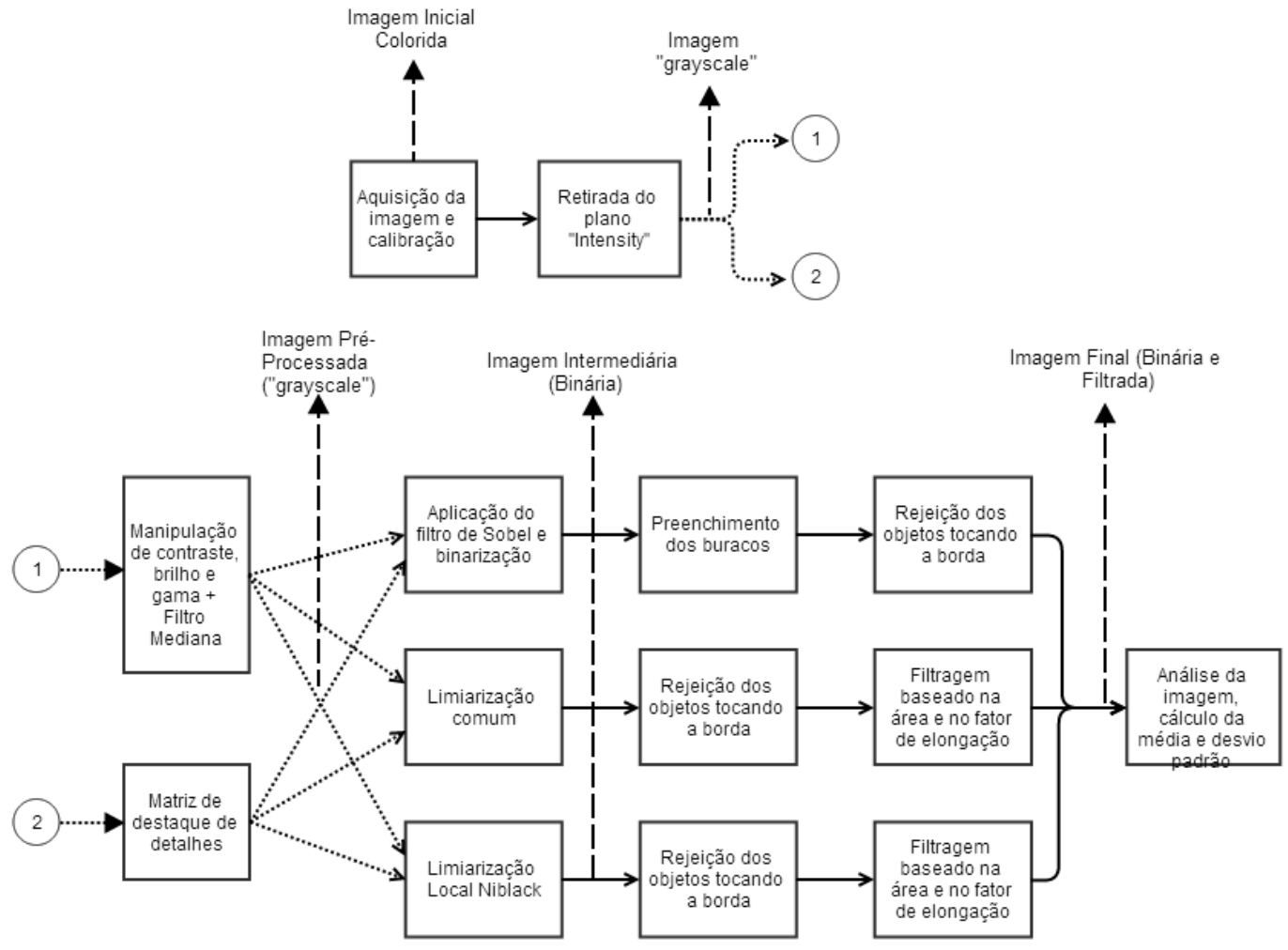


\section{RESULTADOS EXPERIMENTAIS}

No trabalho foram desenvolvidos diferentes algoritmos de processamento de imagem os quais incluem diversas funcionalidades e permitem com relativa eficiência caracterizar os detritos presentes no fluido de perfuração de poços de petróleo. $\mathrm{O}$ tempo de resposta depende do número e combinação de filtros e funcionalidades utilizadas, sendo possível processar cerca de 3 ou 4 imagens por segundo, o que foi considerado suficiente para a aplicação.

O sistema desenvolvido foi utilizado para processar imagens capturadas de peneira vibratória transportando grande número de partículas com dimensões variadas. Serão apresentados os resultados obtidos quando da aplicação de uma janela para definição da região de interesse. As Figuras 4 e 5 mostram um exemplo de imagem utilizada nos testes do algoritmo com destaque para a região de interesse.

Figura 4 - Imagem utilizada nos testes do algoritmo em LabVIEW $^{\mathrm{TM}}$ - Imagem com delimitação da região de interesse

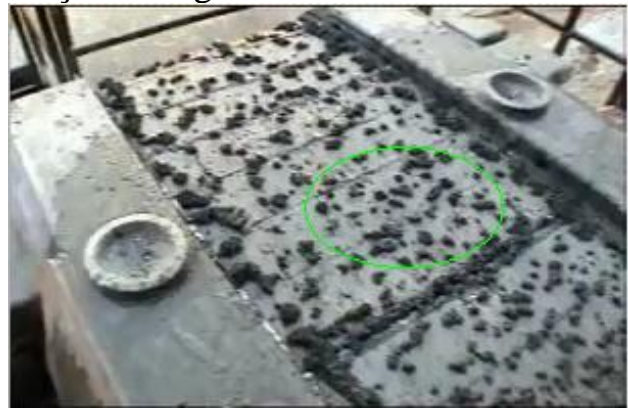

Figura 5 - Destaque da região de interesse da imagem

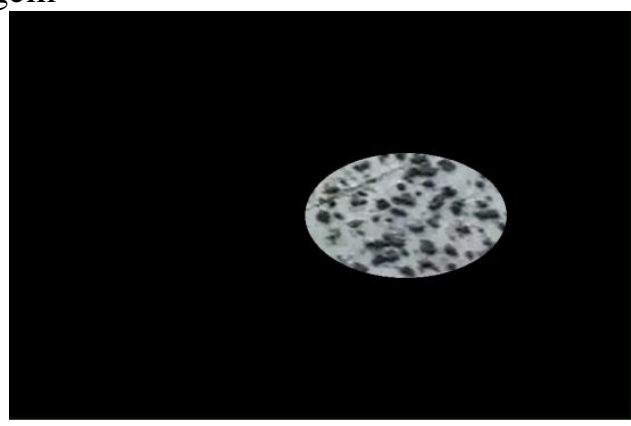

A Figura 6 apresenta alguns resultados obtidos utilizando as seguintes combinações das funcionalidades disponíveis no algoritmo: (a) binarização aplicando algoritmo de destaque de detalhes e filtro de Sobel; (b) binarização aplicando algoritmo de destaque de detalhes, limiarização global e filtro de partículas; (c) binarização aplicando algoritmo de destaque de detalhes, limiarização local com filtro morfológico e filtro de partículas; (d) binarização com manipulação de contraste, brilho e gama, limiarização global e filtro de partículas.

Figura 6 - Resultados obtidos no aplicativo em LabVIEW ${ }^{\mathrm{TM}}$

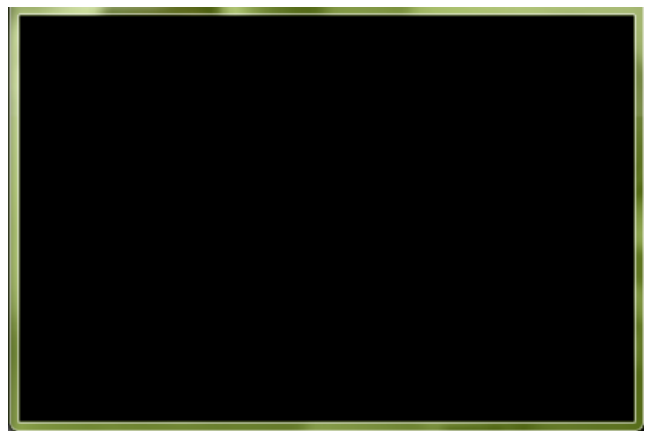

(a)

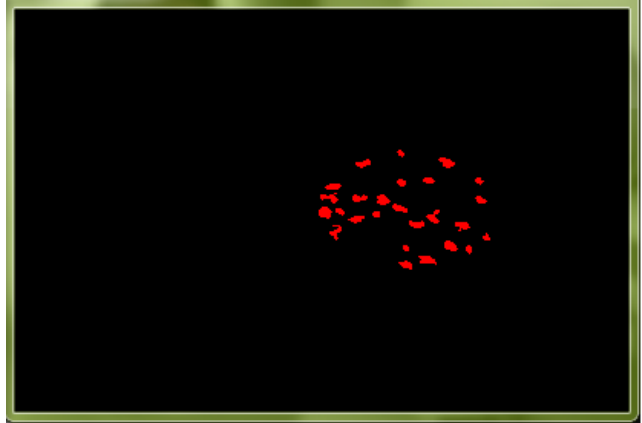

(b)

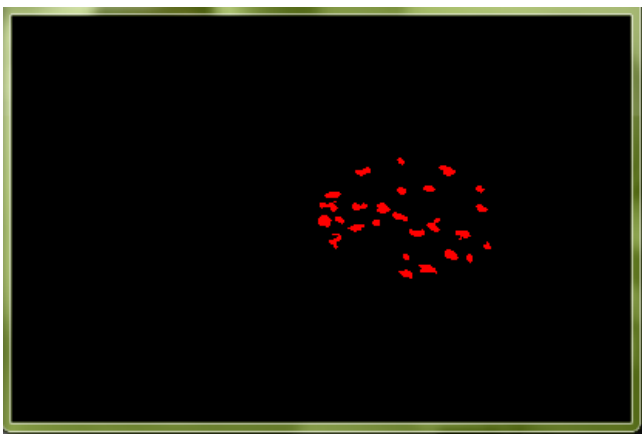

(c) 


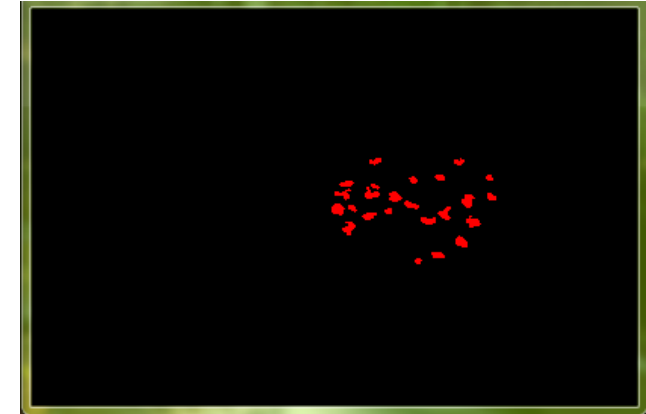

(d)

Analisando as imagens apresentadas na Figura 6, verifica-se que:

a) Ao aplicar filtros de Sobel, o erro obtido foi de $100 \%$. Isso ocorre, pois ao aplicar Sobel poucos contornos haviam se fechado. Sendo assim, quando o algoritmo tenta preencher os buracos, ele preenche um buraco muito grande ou não preenche nada. Logo é eliminado pelo filtro de área ou elongação. Esse fenômeno ocorre ocasionalmente, pois o aplicativo foi testado com outras imagens, selecionando-se a mesma região de interesse e o método forneceu resultados adequados.

b) Nos resultados apresentados, excluindo-se o método que aplicou Filtro de Sobel, o número de objetos encontrados oscilou nos métodos testados entre 24 e 26 . O número real de objetos na imagem é 26.

A Tabela 2 apresenta um resumo dos resultados obtidos. Observa-se que, embora o filtro de Sobel seja eficiente na detecção de bordas, a identificação de partículas produziu resultado nulo. Contudo, desprezando esse resultado, os outros métodos apresentaram excelentes resultados, inclusive com relativa precisão no cálculo da área das partículas identificadas.

Tabela 2 - Resultados obtidos no software LabVIEW $^{\mathrm{TM}}$ para as imagens da Figura 6.

\begin{tabular}{ccc}
\hline Imagem & $\begin{array}{c}\mathrm{N}^{\mathrm{o}} \text { de Objetos } \\
\text { Identificado }\end{array}$ & Erro (\%) \\
\hline $\mathrm{A}$ & 0 & 100 \\
$\mathrm{~B}$ & 26 & 0 \\
$\mathrm{C}$ & 26 & 0 \\
$\mathrm{D}$ & 24 & 7,7 \\
\hline
\end{tabular}

\section{CONCLUSÕES}

Os algoritmos apresentam eficiência na caracterização de detritos, embora com as seguintes limitações:

- imprecisão nas medições quando há acúmulo de material particulado, sobretudo nas bordas da peneira de vibração e;

- necessidade de intervenção do operador para selecionar a melhor combinação de funções e filtros, visando garantir melhor eficiência no algoritmo.

De qualquer forma, há necessidade de calibração que deve ser realizada pelo projetista a partir da definição das condições de luminosidade locais, que devem ser mantidas dentro do possível mais homogêneas possível utilizando iluminação externa, para garantir melhor eficiência na caracterização das partículas.

Um dos diferenciais de algoritmos desenvolvidos em LabVIEW $^{\mathrm{TM}}$ é a facilidade de integração com outros aplicativos e equipamentos, bem como a funcionalidade de permitir a criação de interfaces que podem ser acessadas remotamente pela Internet. Essa característica pode ser introduzida utilizando a função WebServer que permite habilitar o acesso remoto utilizando um servidor. Isto significa que, utilizando navegadores Web que suportam o protocolo HTTP (Hypertext Transfer Protocol) o próprio usuário poderá monitorar ou até mesmo controlar as variáveis do sistema real. A Figura 7 apresenta a interface criada no LabVIEW $^{\mathrm{TM}}$. Na página criada é apresentada uma breve descrição do aplicativo bem como instruções de utilização. 
Figura 7 - Interface gráfica do aplicativo em LabVIEW ${ }^{\mathrm{TM}}$

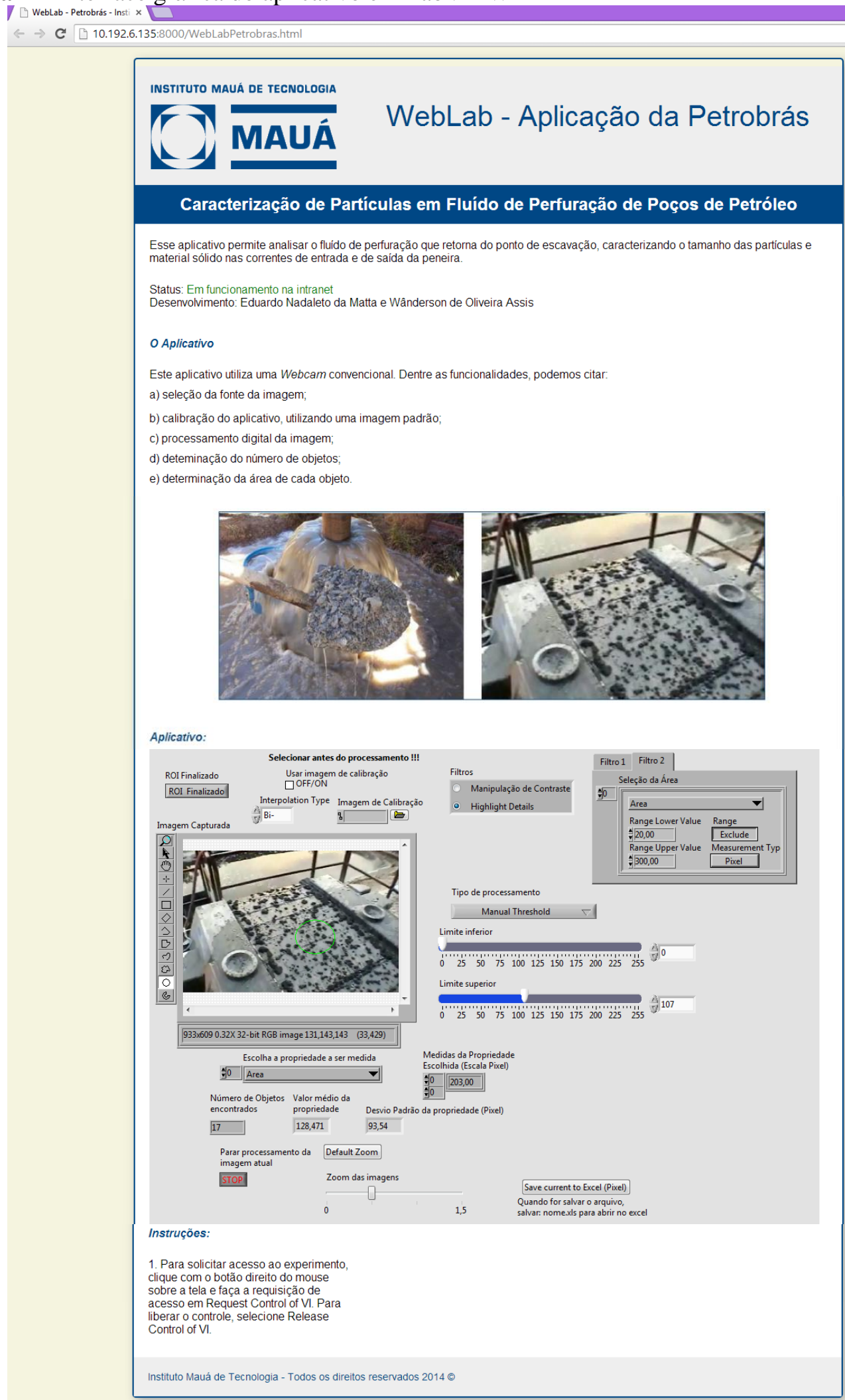




\section{CONSIDERAÇÕES FINAIS}

Embora os algoritmos desenvolvidos não tenham sido efetivamente testados em aplicações reais na exploração de poços de petróleo, os resultados obtidos são relevantes e bastante promissores, demonstrando a viabilidade para implementação.

Espera-se que os principais benefícios advindos da futura utilização do algoritmo em processos de tratamento de fluido utilizado na perfuração de petróleos sejam:

- melhoria na eficiência de remoção de partículas presentes no fluido com consequente redução no impacto ambiental resultante do descarte dos sólidos removidos;

- aumento da vida útil das telas de filtração resultantes da otimização das condições operacionais das esteiras a partir da caracterização das partículas presentes;

- facilidade de monitoramento do processo a distância com a utilização de interface remota.

\section{REFERÊNCIAS}

ALMEIDA, E. L. F. Dinâmica Tecnológica das Indústrias Energéticas. Instituto de Economia/UFRJ. Rio de Janeiro: Mimeo, 2002.

ASME - Shale Shaker Committee of the American Society of Mechanical Engineer. Drilling Fluid Processing Handbook. Gulf Professional Publishing; 1 edition, December, 2004.

COELHO, D. K., ROISENBERG, M., FREITAS FILHO, P. J., JACINTO, C. M. C. Risk Assessment of Drilling and Completion Operations in Petroleum Wells Using a Monte Carlo and a Neural Approach Network Approach, WSC'05: Proceedings of the $37^{\text {th }}$ Conference on Winter Simulation, Winter Simulation Conference, 2005, pp. 1892 1897.
DENIS, C.; ASSIS, W. O.; COELHO, A. D. Sorting Tomatoes for Industrial Processing Through of Computer Vision System Based on Neural Networks, Anais COBEM 2009 International Congress of Mechanical Engineering, Gramado, RS, 2009.

GALP ENERGIA. Perfuração. Galp Energia. Disponivel em: <http://www.galpenergi a.com/PT/investidor/ConhecerGalpEnergia/O s-nossos-negocios/Exploracao-Producao/fund amentos-engenharia-petroleo/Paginas/Perfura cao.aspx>. Acesso em: 24 nov. 2013.

GONZALEZ, R. C., e WOODS, R. E., Processamento de Imagens Digitais, Editora Edgard Blücher Ltda, 2000.

GUERREIRO, F. S. Dimensionamento e especificação técnica de equipamentos a serem instalados em unidade experimental de tratamento de fluido de perfuração automatizada, 2013, 40p. Projeto de Graduação em Engenharia Química Universidade Federal de Uberlândia, Uberlândia, 2013.

GUILHERME, I. R., MARANA, A. N., PAPA, J. P., CHIACHIA, G., AFONSO, L. C. S., MIURA, K., FERREIRA, M. V. D., TORRES, F. Petroleum Well Drilling Monitoring Through Cutting Image Analysis and Artificial Intelligence Techniques. Engineering Applications of Artificial Intelligence, 2011, vol. 24, pp. 201-207.

KIMMEL, R.; SHAKED, D.; ELAD M.; SOBEL, L. Space-dependent Color Gamut Mapping: A Variational Approach. IEEE Transactions on Image Processing, v. 14, n. 6, p. 796-803, Junho 2005.

LOBATO, F. S., OLIVEIRA-LOPES, L. C., Gedraite, R., NEIRO, S. M. S., MURATA, V. V., SÁ, C. H. M. Identificação de Modelos 
para Unidades de Tratamento de Fluido de Perfuração. Anais ENAHPE - IV Encontro Nacional de Hidráulica de Poços de Petróleo e Gás, Foz do Iguaçu - PR, 2011.

PEREIRA, B. L. V. Especificação técnica de sistema de controle de peneira instrumentada aplicada a unidades de tratamento de fluido de perfuração, 2013, 57p. Projeto de Graduação em Engenharia Química - Universidade Federal de Uberlândia, Uberlândia, 2013.

SERAPIÃO, A. B. S., MENDES, J. R. P., MIURA, K. Sistema de Visão Computacional para Detecção de Cascalho de Perfuração em Poços de Petróleo. Anais $6^{\circ}$ Congresso Brasileiro de $P$ \& D em Petróleo e Gás, 2013.

\section{AGRADECIMENTOS}

Os autores agradecem ao IMT, à UFU, ao $\mathrm{CNPq}$ e à PETROBRÁS pelos recursos concedidos e apoio em pesquisas no projeto referente ao termo de cooperação $\mathrm{N}^{\circ}$ 0050.0078502.12.9. 